\title{
Bonding to aged surfaces: a thermally-aged epoxy
}

\author{
MICHAEL G. SPORER, RICHARD E. ROBERTSON \\ Department of Materials Science and Engineering, University of Michigan, Ann Arbor, \\ Michigan 48109-2136, USA
}

It is common experience that aged surfaces are often difficult to bond to. We report an examination of bonding to thermally-aged epoxy surfaces, using as the adhesive the same epoxy as that of the aged surface. The cured and postcured epoxy was aged at $200^{\circ} \mathrm{C}$, with the ageing time varying from 2 to $8 \mathrm{~h}$. The fracture energy of the bond line was measured by mode $\mathrm{I}$ cleavage under conditions of relatively slow crack growth. The bondline fracture energy was found to decrease logarithmically with ageing time. The fracture energies for bonds to surfaces aged for 2,4 , and $8 \mathrm{~h}$ at $200^{\circ} \mathrm{C}$ were $0.077,0.059$, and $0.050 \mathrm{~kJ} \mathrm{M}^{-2}$, respectively. These compare to $0.13 \mathrm{~kJ} \mathrm{M}^{-2}$ for a bond to an unaged surface and $0.21 \mathrm{~kJ} \mathrm{~m}^{-2}$ for bulk fracture. Fracture surfaces resulting from both slow and rapid fracture were examined by optical and scanning electron microscopy. Fracture features different from those arising from bulk fracture were found. Areas with 'good' adhesion occurred amidst fields of featureless fracture surface; the frequency and size of these areas decreased with increased ageing time. Evidence of plastic deformation was found, always occurring on the new side of the bond: ridges parallel with crack propagation at high crack speeds and subsurface undulations perpendicular to crack propagation at low speeds. The bond has the effect of channelling the crack along the bondline, but fracture does not always remain exactly at the interface. Fracture often occurred a relatively constant distance away from the interface, suggesting that the presence of the interface was felt for some distance.

\section{Introduction}

Aged surfaces are often difficult to form adhesive bonds to. Empirical recipes and prescriptions for overcoming the problem have been developed, which usually involve mechanical removal from the surface of a layer of material. But the cause of the problem itself is not well understood. In the present work, we have attempted first to quantify the problem of poor adhesion to aged surfaces, and second to describe the morphological characteristics of the fracture surfaces resulting from failure of these bonds. The work was suggested by our program of composite structure repair, and the system chosen for study was an epoxy cured with a common aromatic amine. Epoxies are widely used for both matrix resins for structural composites as well as for adhesives. In the present work, both the aged surface being bonded to and the bonding adhesive were the same material.

Ageing was accomplished in the present work by a relatively short-time exposure to high temperature. Besides being a simple way of accelerating ageing, exposure to high temperature is often encountered by epoxy matrix resins in service. To quantify adhesion, the fracture energy of the bonds were measured by mode I cleavage. The fracture energies of bonds to aged surfaces were compared with those of bonds to unaged surfaces, as well as to those of bulk fracture.

The resulting fracture surfaces were examined in detail using optical and scanning electron microscopy (SEM). The characterization of the fracture surfaces of bulk epoxies has received wide study [1-4]. But there is scant literature on the characterization of epoxy bonds. A comparison of bulk epoxy fracture surfaces with those fracturing along the bond interface reveals that interface surfaces seldom exhibit significant features. The surfaces tend to be vast planes of smooth material with occasional evidence of adhesion. Bulk fracture surfaces, on the other hand, typically have the basic longitudinal texture and step/welt features. But the occasional evidences of adhesion along the bond interface offer landmarks for finding and comparing mating fracture surfaces. The mating surfaces show little loss of material during fracture. When the fracture leaves the interface, creating a cavity on one side, the material from that cavity remains firmly adhered to the mating surface. Being unique in appearance, they act as landmarks that make comparisons between the mating surfaces possible.

\section{Experimental procedures}

\subsection{Materials}

The materials studied were epoxy resins physically aged for different amounts of time. The resin system was prepared from Shell Chemical's Epon 828 diglycidyl ether of bisphenol-A (DGEBA) epoxy resin which was mixed with a stoichiometric 20 p.h.r. (parts 
per one hundred resin) of Shell Curing Agent Z, an aromatic amine. This combination of resin and curing agent and mixing ratio was chosen because the resin and curing agent contain few additives, and result in a highly cross-linked cured resin that is extremely stable at elevated temperatures.

\subsection{Specimen preparation}

The specimens were prepared in a bilayer, consisting of a resin-curing agent system that was bonded to a cured slab of the same system. Hence the second layer is its own adhesive; no other adhesive layer was involved.

The resin and curing agent were mixed on a hot plate to reduce the viscosity for ease of mixing. After mixing the first batch, it was poured into a shallow tray measuring $\sim 10$ by $\sim 25 \mathrm{~cm}$ to a depth of $0.9 \mathrm{~cm}$. The tray was immediately placed in an air-circulating oven to cure. The curing schedule was $80^{\circ} \mathrm{C}$ for $2 \mathrm{~h}$ followed by a post-cure of $150^{\circ} \mathrm{C}$ for $2 \mathrm{~h}$, as recommended for optimum properties by the "EPON Resin Systems Handbook".

After curing and postcuring, the slabs were removed from the tray and divided laterally into four sections. The surface exposed to the atmosphere was the surface to be bonded to. The specimens were handled with great care to avoid touching this surface. After dividing the specimens, the four sections were thermally aged for different amounts of time at elevated temperatures. The schedule of ageing time is given in Table I.

Before ageing, the surfaces were blown clean with a compressed gas duster. All ageing was performed in an air-circulating oven at $200^{\circ} \mathrm{C}$. After ageing, the specimens were rinsed with water, followed by acetone, and dried with forced warm air. The surfaces appeared mirror-like to the naked eye. The specimens were returned to the tray with the surface to be bonded up. A second batch of resin was mixed and poured on top of the free surfaces of the cured and aged slabs to a depth of $0.9 \mathrm{~cm}$. The specimens were returned to the oven for curing and postcuring using the same schedule.

The slabs were again divided laterally to give the bilayer specimens. These measured (after the sides and ends were made flat and square) $\sim 9 \mathrm{~cm}$ long by $1.3 \mathrm{~cm}$ wide by $1.8 \mathrm{~cm}$ thick, with the bond in the middle of the thickness. Four specimens were produced from each ageing group.

Specimens for measuring the fracture energy of the bulk material were prepared simultaneously in an identical tray by filling the tray to a depth of $1.8 \mathrm{~cm}$. The bulk specimens underwent curing, postcuring, division, ageing, and a second cure and postcure at the

TABLE I Schedule of ageing time at $200^{\circ} \mathrm{C}$

\begin{tabular}{ll}
\hline $\begin{array}{l}\text { Specimen } \\
\text { designation }\end{array}$ & Ageing time $(\mathrm{h})$ \\
\hline 0 & 0 \\
I & 2 \\
II & 4 \\
III & 8.1 \\
\hline
\end{tabular}

same time and in the same oven with the bilayer specimens.

For quantitative testing, it was essential to encourage stable crack propagation. To achieve this it is necessary to machine a channelling groove down both sides of the specimen. The groove was centred on the bondline and measured 2 by $4 \mathrm{~mm}$. To initiate fracture, a starter notch was machined in the end of the specimen, centred on the bondline. The notch was $0.25 \mathrm{~mm}$ wide and $\sim 3 \mathrm{~mm}$ deep. The final requirement to achieve stable propagation was to initiate the crack along the bond, which was accomplished by driving a razor blade into the bondline. The razor blade was held in a clamping device to achieve a consistent penetration of $1 \mathrm{~mm}$, which was usually sufficient to initiate a sharp crack that would propagate in a stable manner.

\subsection{Fracture mechanics measurements}

Fracture mechanics measurements were made by measuring the crack opening displacement and the crack length while imposing mode I fracture along the bondline. Cleavage stresses were imposed by driving a wedge into the starter notch on the end of the specimen. The wedge was driven by an Instron machine. The crosshead speed was $0.051 \mathrm{~mm} \mathrm{~min}^{-1}$. A single layer of Teflon tape was used to minimize friction between the specimen and wedge. The fracture energy and the fracture toughness were determined from the following equations [5]

$$
G_{\mathrm{Ic}}=\frac{K_{\mathrm{Ic}}^{2}}{E}
$$

and

$$
K_{\mathrm{jc}}=\frac{\sqrt{3} E h^{3 / 2} \delta}{2 \mathrm{c}^{2}\left(1+0.64 \frac{h}{c}\right)^{2}}
$$

where $K_{\mathrm{Ic}}=$ fracture toughness $(\mathrm{MPa} \sqrt{\mathrm{m}})$; $G_{\mathrm{lc}}=$ fracture energy $\left(\mathrm{kJ} \mathrm{m}^{-2}\right) ; E=\operatorname{modulus}(\mathrm{MPa})$; $h=$ beam thickness; $d=$ top opening displacement; $\delta=d / 2-h$ (one-half crack opening displacement); $c=$ crack length. Figure 1 illustrates the two measurements taken during testing. Due to the need for the initiator notch at the top of the specimen, the portion of the specimen from the top to the depth of the starter notch has a lower stiffness. This can be corrected for using cantilever beam theory. The effects of the notch on fracture toughness were corrected by using [6]

$$
\begin{gathered}
K_{\mathrm{lc}}=\frac{\sqrt{3} E h^{3 / 2} \delta}{2_{c}^{2}\left(1+0.64 \frac{h}{c}\right)^{2}} \\
\times\left\{1+\left[\left(\frac{h}{h^{\prime}}\right)^{3}-1\right]\left(\frac{l}{c}\right)^{3}\right\}^{-1}
\end{gathered}
$$

where $h^{\prime}=$ thickness of reduced beam section and $l=$ depth of notch. Fig. 2 shows the measurements necessary for this equation. A number of fracture energy measurements were made on each specimen, as long as the crack tip was within roughly the central three-fifths of the specimen length. The crack tip location was recorded prior to each crack propagation. The wedge was driven downward, and when 


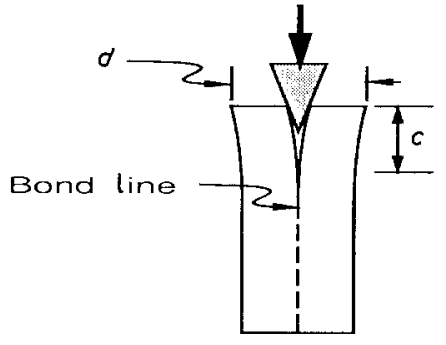

Figure 1 Geometry of general fracture energy test specimen. The crack length, $c$, and top opening displacement, $d$, were measured immediately following each propagation of the crack.

the crack began to grow, the machine was immediately stopped and the top opening displacement measured. These measurements allow $c$ and $\delta$ to be calculated. After the specimen was broken into two pieces, the fracture surfaces were examined to verify that fracture had occurred completely at the interface. Those test results where the fracture strayed from the interface were discarded. The topography of the fracture surface was such that this determination was possible.

\subsection{Fractography}

The fracture surfaces were examined both optically and with a scanning electron microscope. Prior to SEM analysis, the fracture surfaces were coated with a gold-palladium layer. The SEM employed was a Hitachi S-520, operating at an accelerating voltage of $15 \mathrm{keV}$. The optical microscope was a Nikon Optiphot Metallurgical Microscope using bright field, dark field, and cross-polarized light. When photographing surfaces using polarized light, each micrograph was taken with the polarizer and analyser crossed.

\section{Results}

\subsection{Fracture Energy}

As described above, the fracture energy was obtained from the crack opening displacement required to cause crack propagation in the cleavage test shown in Fig. 1. Fracture energy measurements were made on bonded specimens and, for comparison, on bulk (bond-less) specimens. Due to the nature of the test and the brittleness of the material, achieving stable crack propagation was challenging. There was considerable tendency for the crack to run away from the grooved part of the specimen.

Fig. 3 shows the fracture energy on bulk specimens

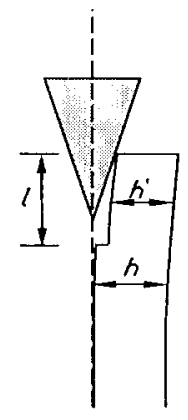

Figure 2 Geometry of fracture energy specimens used. Beam section thickness, $h$, is measured before testing and is one-half full specimen width. The notch depth, $l$, and reduced section thickness, $h^{\prime}$, were measured after testing.

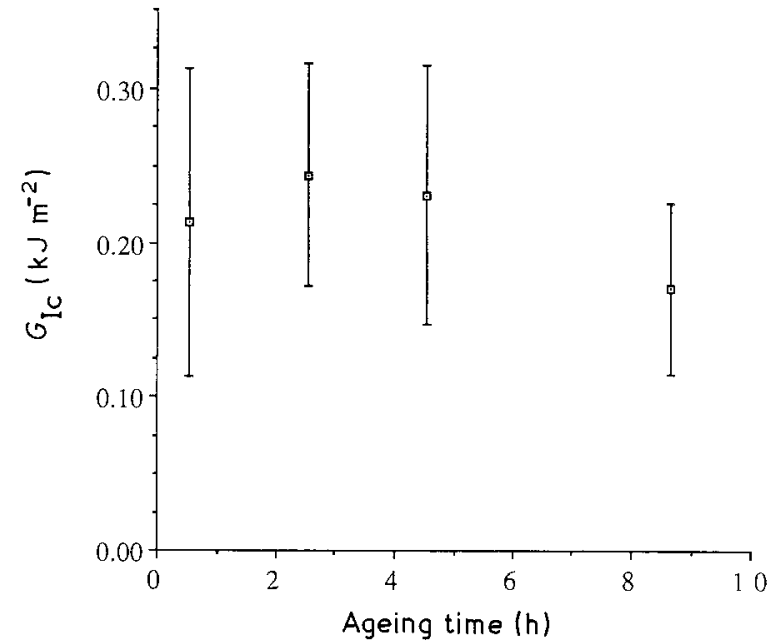

Figure 3 Fracture energy of bulk (bondless) material against ageing time. Ageing times have been adjusted for cure and postcure.

against ageing time at $200^{\circ} \mathrm{C}$. The mean fracture energy for the bulk material, irrespective of ageing, was $0.21 \mathrm{~kJ} \mathrm{~m}^{-2}$. Error bars of \pm 1 S.D. of the data for each ageing time are also indicated in Fig. 3 and are seen to be large. Although a trend for the mean fracture energy against ageing time might seem to be suggested, no trend other than a straight, horizontal line is statistically significant. An attempt was made to include for the older of the two layers an equivalent ageing time at $200^{\circ} \mathrm{C}$ for the additional exposure to the cure and post-cure conditions. This was taken, as will be explained below, to be equivalent to $0.55 \mathrm{~h}$.

Fig. 4 shows the fracture energy required for crack growth along the bondline against ageing time at $200^{\circ} \mathrm{C}$. The diamonds in Fig. 4 refer to the nominal ageing time of the specimens, the time at $200^{\circ} \mathrm{C}$ only. The open squares take into account the time that the older of the two layers was exposed to the conditions of cure and post-cure. The mean fracture energies for the four specimen ages denoted by 0 , I, II, and III were $0.13,0.077,0.059$, and $0.050 \mathrm{~kJ} \mathrm{~m}^{-2}$, respectively. The error bars of \pm 1 S.D. are seen to decrease in size with increasing ageing time. A more stable crack propagation is achieved as the weakening of the bondline with ageing results in less tendency for the crack

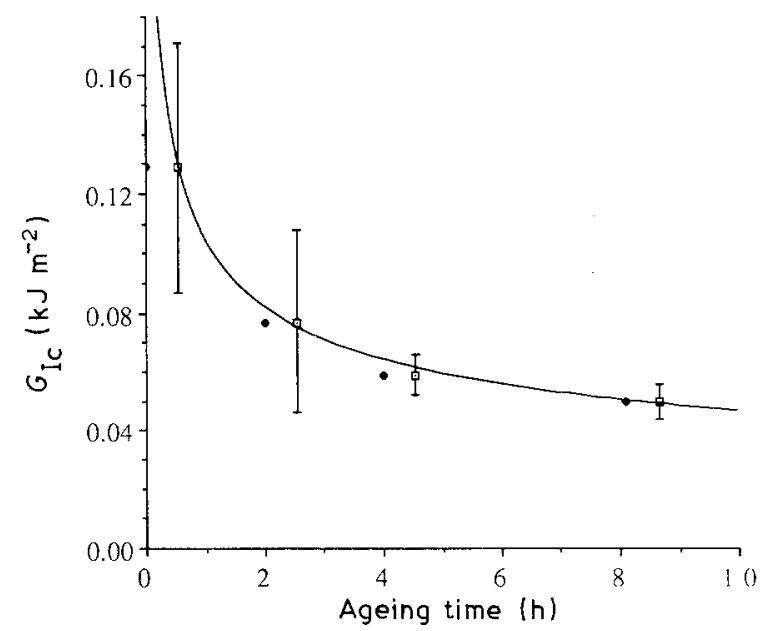

Figure 4 Fracture energy of bond line against ageing time. Fracture energy shows logarithmic correlation with ageing. $\bullet$. Age; $\square$, age corrected. 


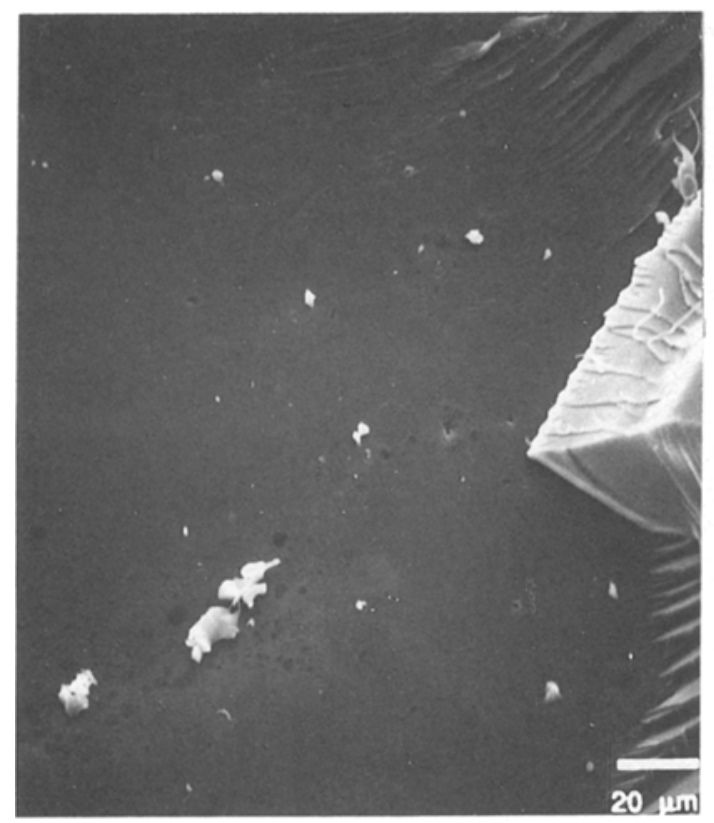

Figure 5 SEM micrograph of the transition from bulk to interfacial fracture, Crack propagation is from right to left. The expected abrupt transition, lighter in colour, is seen at the centre-right. Above it is a feathered approach of the crack from the bulk to the interface.

to leave the bond. The curve drawn through the data is a best fit to a logarithmic equation. This curve, with a correlation coefficient $R^{2}=0.995$, is given by

$$
G_{\mathrm{lc}}=0.105\left(^{\prime A g e '}+0.55\right)^{-0.351}
$$

where $G_{\mathrm{Ic}}$ is in $\mathrm{kJ} \mathrm{m}^{-2}$ and 'Age', the time at $200^{\circ} \mathrm{C}$, is in $\mathrm{h}$. As mentioned above, the value of $0.55 \mathrm{~h}$ represents an equivalent ageing during the curing and post-curing processes, but its magnitude was chosen to give the best fit to the logarithmic equation.

\subsection{Fractography: approaching the interface}

The fracture surfaces examined were from three specific areas: (i) where the crack approached the interface from the bulk; (ii) where the crack ran along the interface; and (iii) where the crack left the interface for the bulk. Each fracture created two surfaces; a total of six areas of interest were examined.

The bond interface generally has a strong channelling effect on the path of fracture. As a result, there is a tendency for the crack to jump towards the interface whenever the crack in the bulk strays within the influence of the bond line. This effect is observable in Fig. 5 at the right-centre of the micrograph, where there was an abrupt transition from the bulk to the bond line.

Often, however, the channelling effect of the bond line seems to be muted. Alongside the region of the abrupt transition to the bond line in Fig. 5 are two areas of a smooth or feathered approach. These appear along the right edge of the micrograph, just above and below the abrupt transition. A better view of the feathering of the approaching crack is seen in Fig. 6. The crack approaching the interface from the bulk epoxy is seen to feather out onto the interface for a distance of the order of $50 \mu \mathrm{m}$. The boundary where

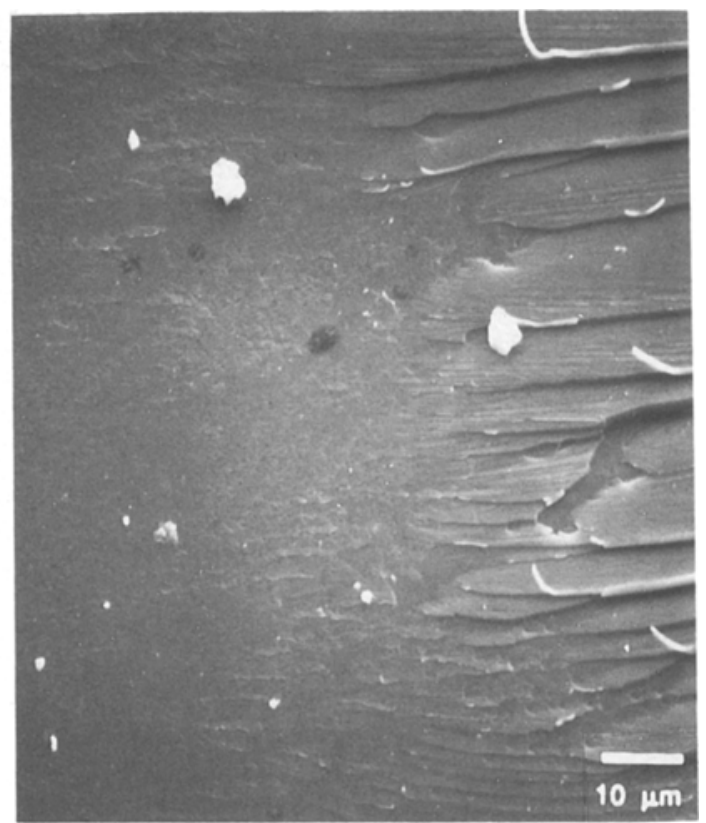

Figure 6 SEM micrograph of the transition of crack growth from the bulk to the interface. Crack propagation is from right to left, from the rough area to the bond interface, feathering onto the bond interface.

the feathering process ends in Fig. 6 is somewhat irregular, but is roughly down the centre of this micrograph. Fig. 7 shows another instance where the feathering process is drawn out for a distance of about $100 \mu \mathrm{m}$. The feathering of the crack onto the interface shows a blending of bulk and interfacial fractures. The fracture surface of the bulk material has such characteristic features as the basic longitudinal texture [7]. As the crack front neared the interface, short lengths of it dipped down onto the interface and exposed small areas of interface, an example of which is visible in Fig. 8, at the locations indicated by the arrows. The

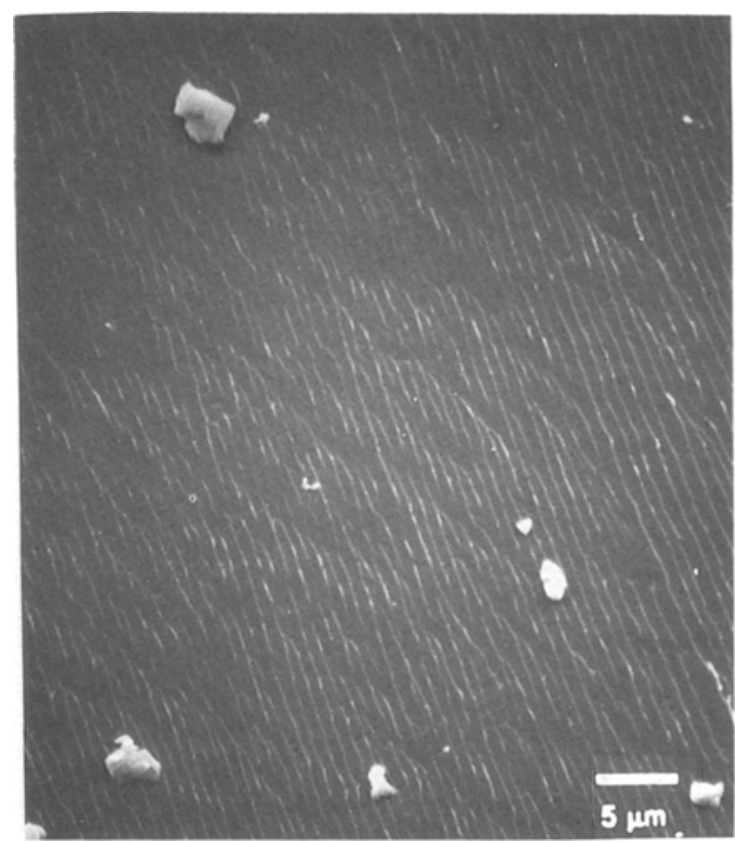

Figure 7 Bulk fracture very near the interface as the crack feathers onto it as the crack travelled nearly parallel with the lines in this micrograph, from lower right to upper left. These features extend for a distance of $\sim 100 \mu \mathrm{m}$ 

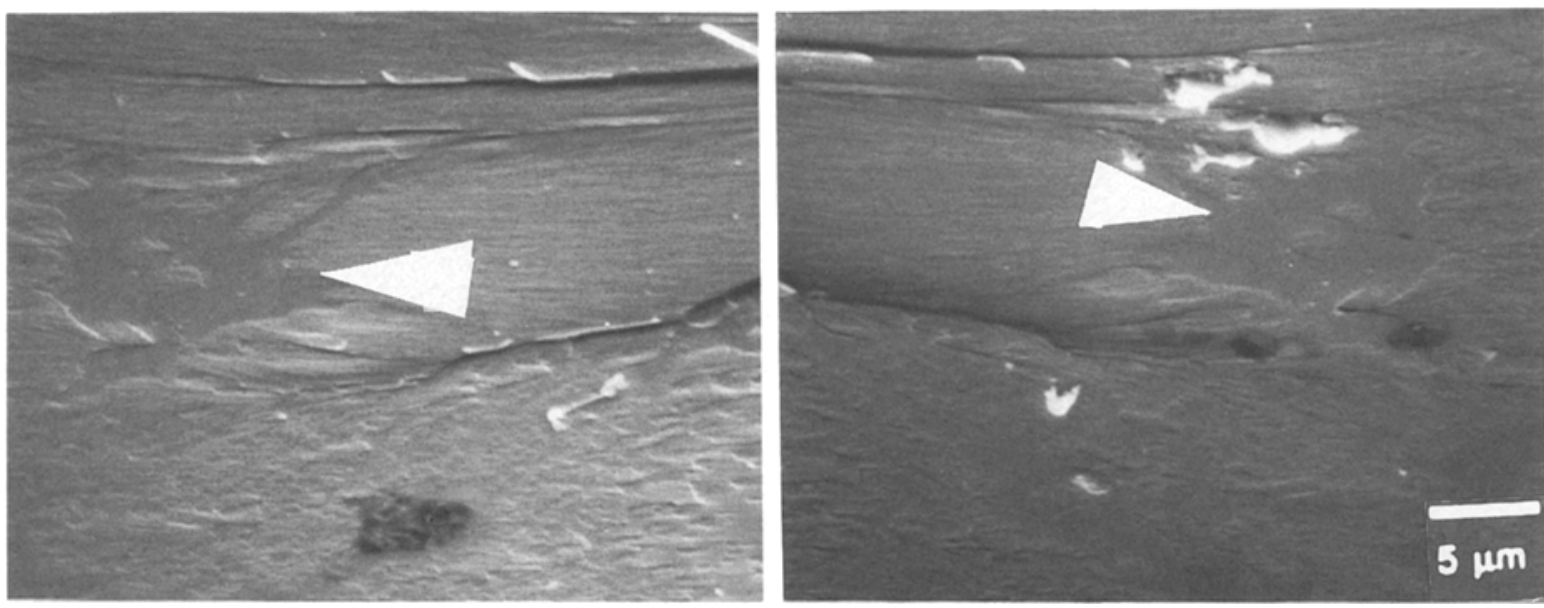

Figure 8 SEM micrographs of mating surfaces showing the crack feathering onto the interface with the crack travelling from the centre of the two photos towards the left and right edges, respectively. Mating areas of interface indicated by arrows.

continued channelling influence of the interface caused the crack subsequently to approach the interface more frequently and in larger areas, until the crack was more on the interface than in the bulk material and eventually was entirely at the interface.

The feathering phenomena showed no affinity for any particular age category nor any specific specimen. Feathering was observed on specimens of all ages and was frequently observed adjacent to areas having an abrupt transition from bulk to bond line, as seen in Fig. 5.

\subsection{Fractography of the interface after low- speed fracture}

The low-speed fracture during the fracture energy measurement consisted of a sequence of crack-growth initiations followed by arrests. Following each initiation, the crack ran freely along the interface until the energy release rate dropped sufficiently to cause the crack to arrest. Between initiation and arrest, crack travel seemed unimpeded along the interface, and the surface appeared mirrorlike to the naked eye. The crack appeared to travel along the interface, but an examination at high magnification with the SEM showed features suggesting that the path of the crack was not solely on the interface nor unimpeded.

After initiation, the crack appeared to propagate for a distance during which a featureless fracture surface was left, although optical micrographs, which are discussed below, show a texture. Then the fracture began to stray from the bond interface into one of the two sides, leaving the layer of fracture debris removed from that side attached to the mating surface, as shown in Fig. 9 of a matched pair of micrographs for an age I specimen. Another example, a matched pair of micrographs for an age III specimen, is shown in Fig. 10. These micrographs give the appearance of droplets drawn out in the fracture direction. After propagating in the bulk a relatively small distance from the interface for some distance, the fracture
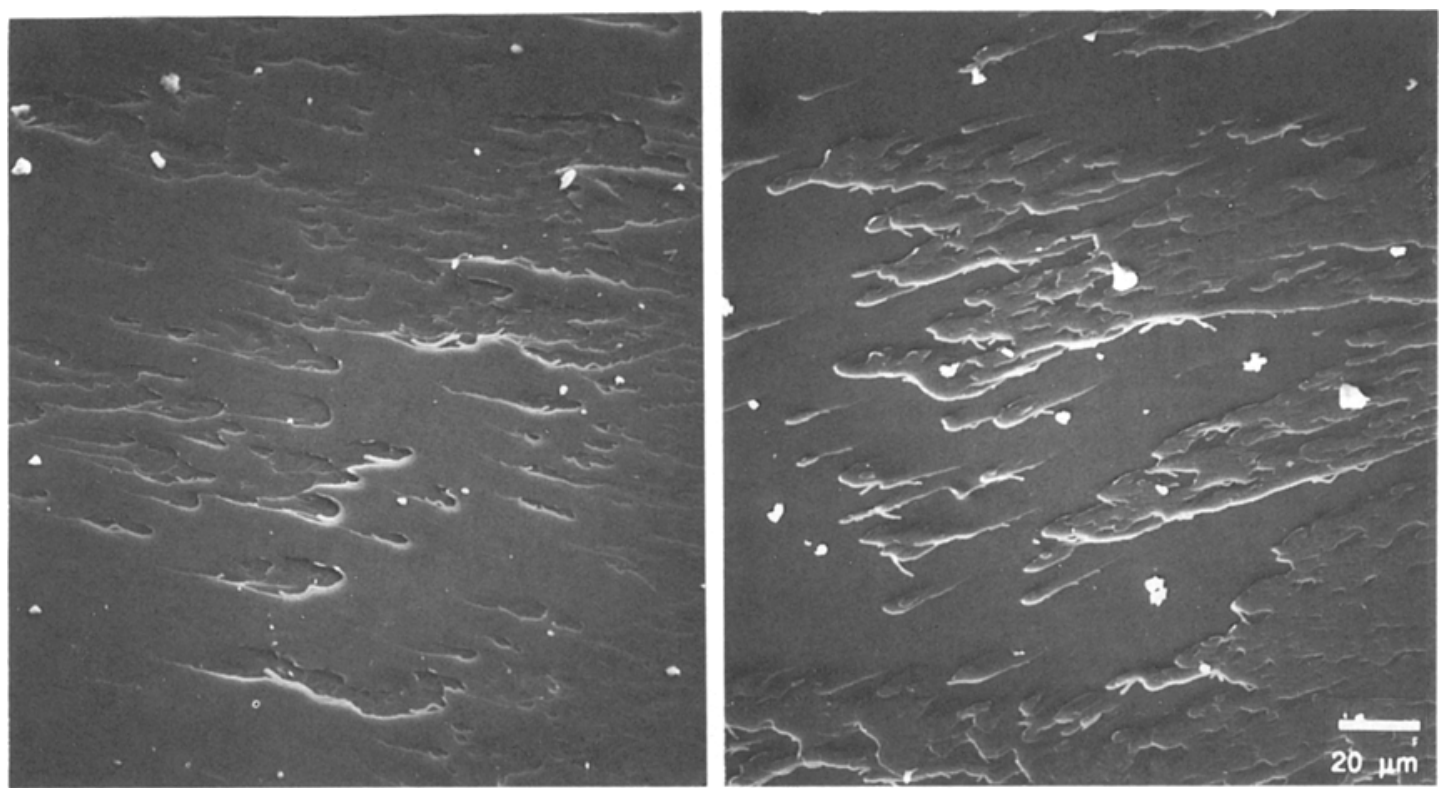

Figure 9 SEM micrographs of surfaces created by slight deviation of the propagating crack from the interface of an age I specimen. The layer of material removed from one surface, $\sim 3 \mu \mathrm{m}$ thick, remains attached to the other. These are not exact mating surfaces, which were not found because of the large areas of the fracture surface that appeared the same as this. Crack growth was from the centre out. 

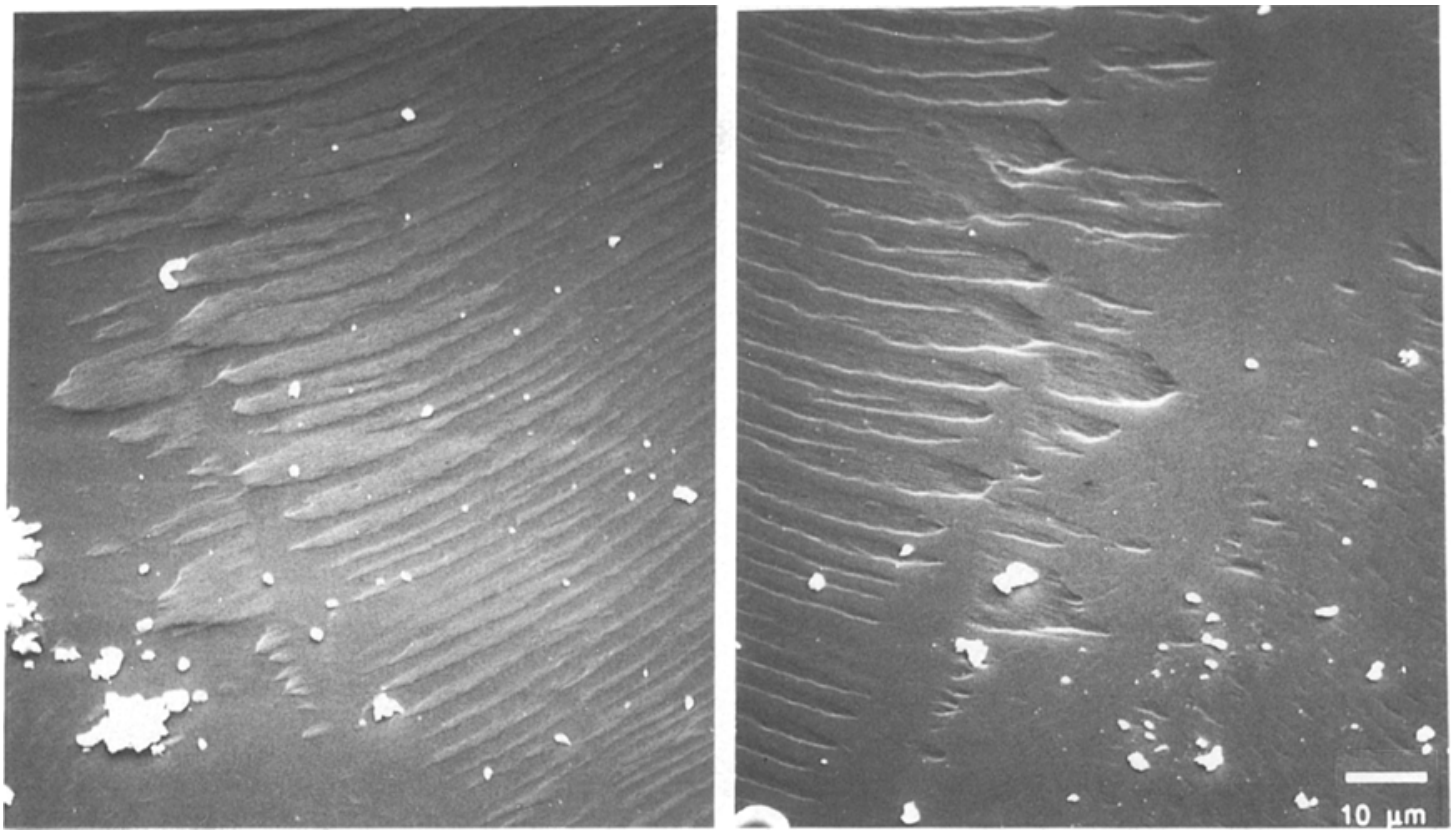

Figure 10 Mating micrographs of an age III interface showing features similar to those in Fig. 9. A skin of material $\sim 1 \mu \mathrm{m}$ thick from one side is attached to the mating surface. Crack growth was from the centre outward and downward.

returned to the interface. The fracture sometimes strayed far enough from the interface to suggest that the crack ran entirely through bulk material. An example is shown in Fig. 11. The surface in Fig. 11 appears to be that of bulk fracture, but there exist small patches where the crack travelled along the interface. These areas appear mirror-like in the micrograph. Eventually, this crack also returned completely to the interface.

In addition to the many instances where the crack path deviated only slightly from the interface, by no more than several micrometres, other instances were found where the crack path made considerably steeper and greater excursions from the interface, by 100 to

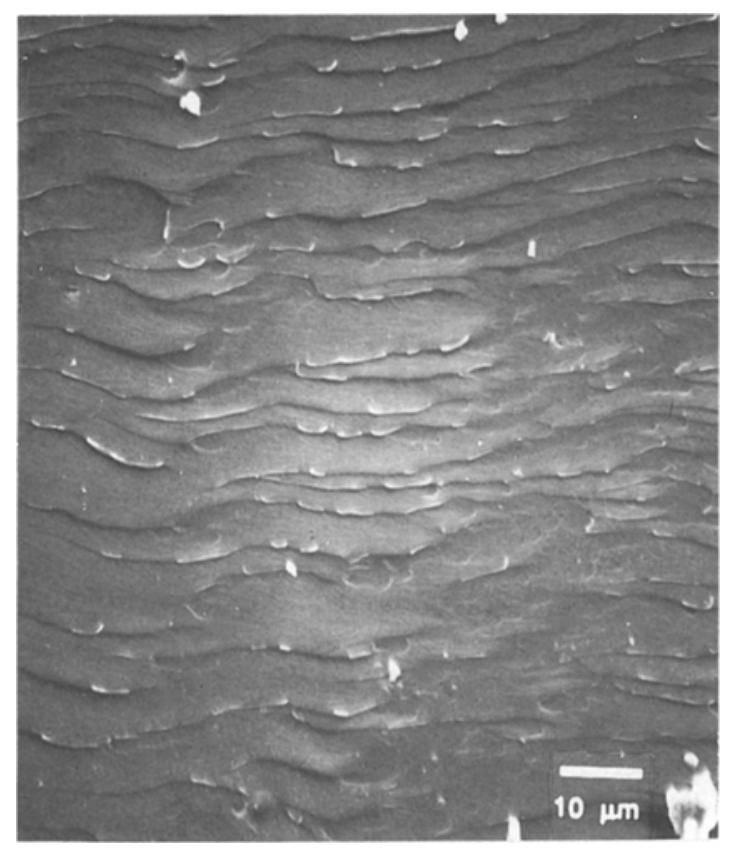

Figure II Fracture surface of age I interface fracture. The crack strayed far enough from the interface to give the appearance of bulk fracture, but small areas of the interface are still visible. The average layer thickness is $\sim 3 \mu \mathrm{m}$. Crack growth was from right to left.
$1000 \mu \mathrm{m}$. Even with the crack leaving the interface at the steep angle of roughly $25^{\circ}$, as seen in Fig 12 , it still returned to the interface after leaving a feature with an altitude of $15 \mu \mathrm{m}$ above the interface. Other instances of large features appearing in the middle of open planes are shown in Fig. 13. Here the crack dove into the 'new' bulk material in the left micrograph, leaving behind a sizeable diamond or square-shaped canyon. All of the material excavated in this process remained firmly adhered to the mating 'old' surface in the right micrograph. The excursion into the bulk near the centre-right edge of the left micrograph might have become quite large, as evidenced by the crack front extremities, but was terminated instead. The crack almost returned fully to the interface, but again deviated into the bulk as it propagated into the lower left corner. Toward the upper part of the left micrograph is another instance of the start of a steep deviation from the interface, which soon terminated.

The roughened region near the centre of the left micrograph of Fig. 13, just downstream from where the pyramid-shaped piece had been plucked from the surface, and its appearance on the matching surface, are shown at higher magnification in Fig. 14. The fracture is of a non-bulk type and suggests that this may have been an area of greater adhesion. The specimen separated at or near the interface, with the material plucked from each surface remaining stuck to the opposite surface. (Most, if not all, of the bulk fracture occurred in the 'new' resin side of the bilayer for both the large and small features). All of the material transferred appears to have undergone substantial plastic deformation.

Another large feature (100 to $1000 \mu \mathrm{m}$ in height) caused by the crack leaving the interface is seen in Fig. 15. A more highly magnified view of the region where the crack left the interface is shown in Fig. 16 and suggests a similar high degree of plastic deformation in the vicinity of the interface. 

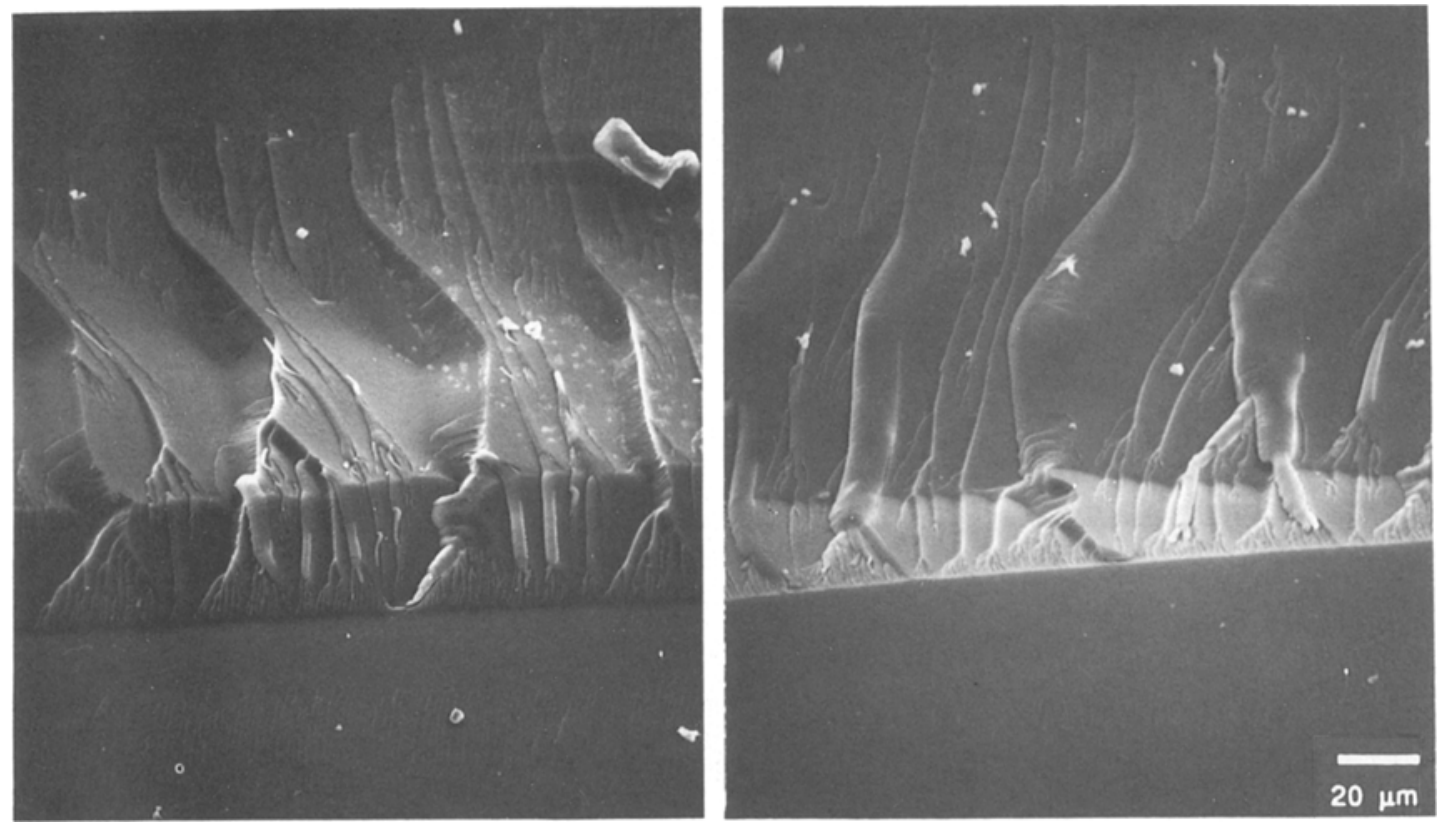

Figure 12 Mating surfaces of an age II specimen. The crack, travelling from bottom to top, abruptly left the interface, perhaps because of a scratch on the surface, but the strong channelling influence of the interface brought the crack back to the interface. The height of this feature is approximately $15 \mu \mathrm{m}$.

Areas away from such large features show mirrorlike surfaces, indicating a brittle interface fracture. These vast expanses of interface are sparsely interrupted with an occasional feature where a small (10 to $40 \mu \mathrm{m})$ but tall chunk is pulled from the interface, as seen in Fig. 17. Thus the crack lifts chunks of material out of one of the surfaces as it travels along the interface. The material removed in this process (usually from the new surface) remains well bonded to the mating (old) surface. These small features are believed to contribute to the fracture energy of these types of fracture.

The large features found on the interfacial surface are common to all age groups. The areas surrounding these features display varying degrees of plastic deformation, usually of the new surface. Other features of the fracture surfaces, such as density of small elements plucked from the surface and the plastic deformation seen optically under crossed-polarized light, varied with ageing.

\subsection{Fractography of the interface after high- speed fracture}

High-speed fracture was induced by driving a chisel with a hammer into a sawcut that was adjacent and parallel with the bond line. The resulting fracture
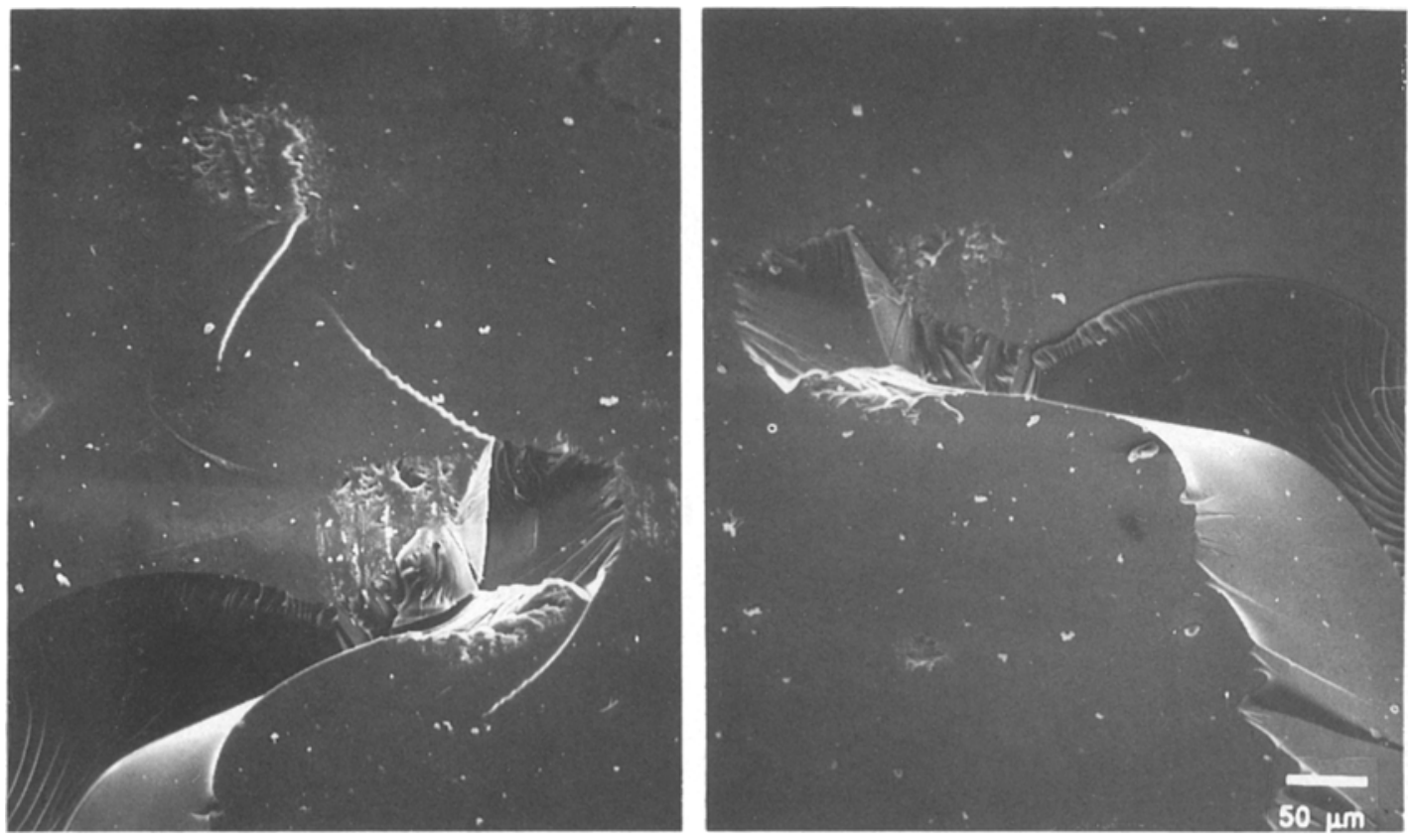

Figure 13 Partially mating surfaces of an age I specimen with two instances of the crack leaving the interface in the left micrograph. The white 'wings' are where the crack left the interface and went into the bulk. In the upper part of the left micrograph are remnants suggesting that the interface lacked sufficient strength to sustain crack propagation in the bulk. Below is another region with terminated cracks in the bulk where the interface had sufficient strength to allow the crack to bifurcate and to remain partially in the bulk. Crack propagation was from the centre outward and downward. The new layer is on the left. 

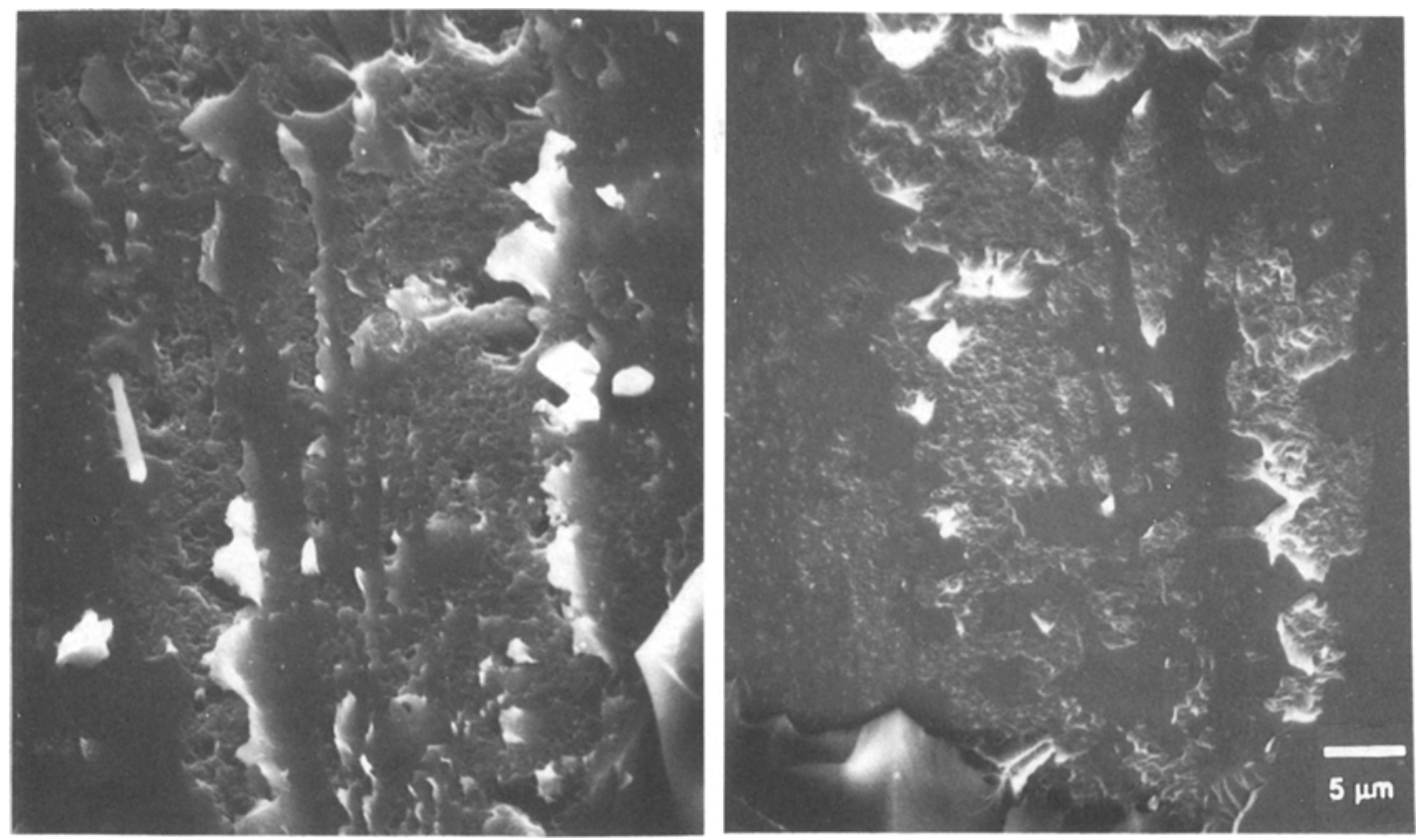

Figure 14 Higher magnification micrograph of Fig. 13, from the rough area near the centre of the left micrograph, showing ductile flow during the fracture in this area. Fracture occurs in the new material, with debris remaining stuck to the old surface.

surfaces are different from those seen on the specimens broken during the fracture energy measurement. In particular, a series of parallel ridges formed by plastic deformation on the interfacial surface was found, as previously described by Robertson et al. [8]. An example is shown in Fig. 18 for an age 0 specimen. The parallel rows run in the fracture direction along the interface. These ridges or rows tend to diverge over large distances. The rows are most closely spaced where the crack enters the interfacial region from the bulk. As the distance along the interface increases, so does the spacing, and eventually the rows simply disappear.

The mating surface, Fig. 19, exhibits a possible texture that is so faint that one cannot determine whether it truly exists or is an illusion in the observer's mind created by the desire to see such a texture. Regardless of whether a texture exists on the mating (older) surface, the most significant portion of the deformation has occurred only on the new side of the interface. Again, note that the 'old' surface in Fig. 19 had not been aged, it had simply been cured and postcured a second time.

Similarities between fracture surfaces of specimens fractured at low and high speed are the strong channelling influence of the interface and of the dispersion over vast interfacial regions of small spots of adhesion, evidenced by small chunks pulled from one surface and remaining firmly bound to the mating surface. These features, as well as smaller such features, can be seen in Fig. 20. This fracture surface is typical also in that the occasional wandering away from the interface
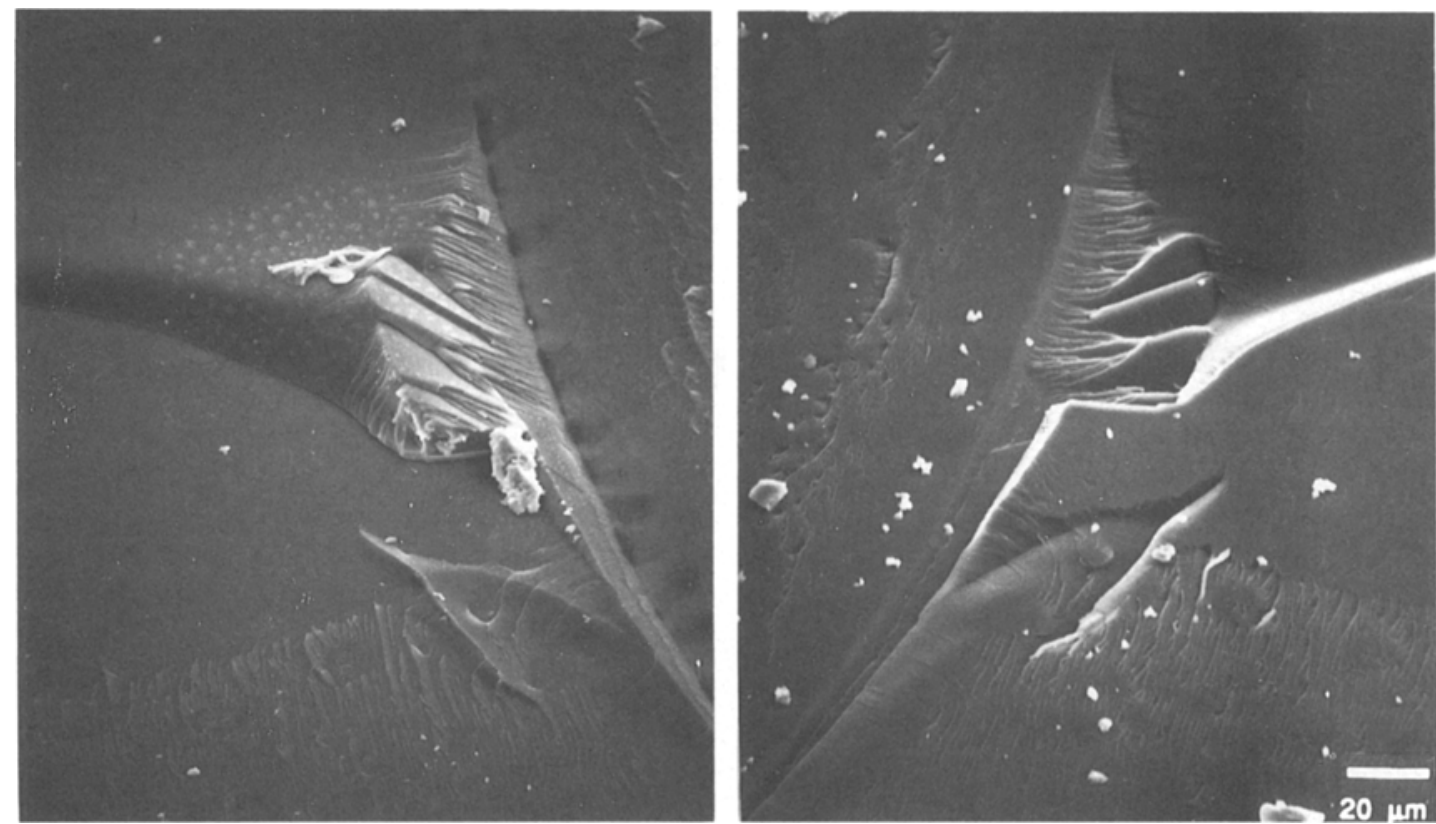

Figure $15 \mathrm{~A}$ large feature left on the interface of an age II specimen, probably caused by an area of high interfacial strength. 

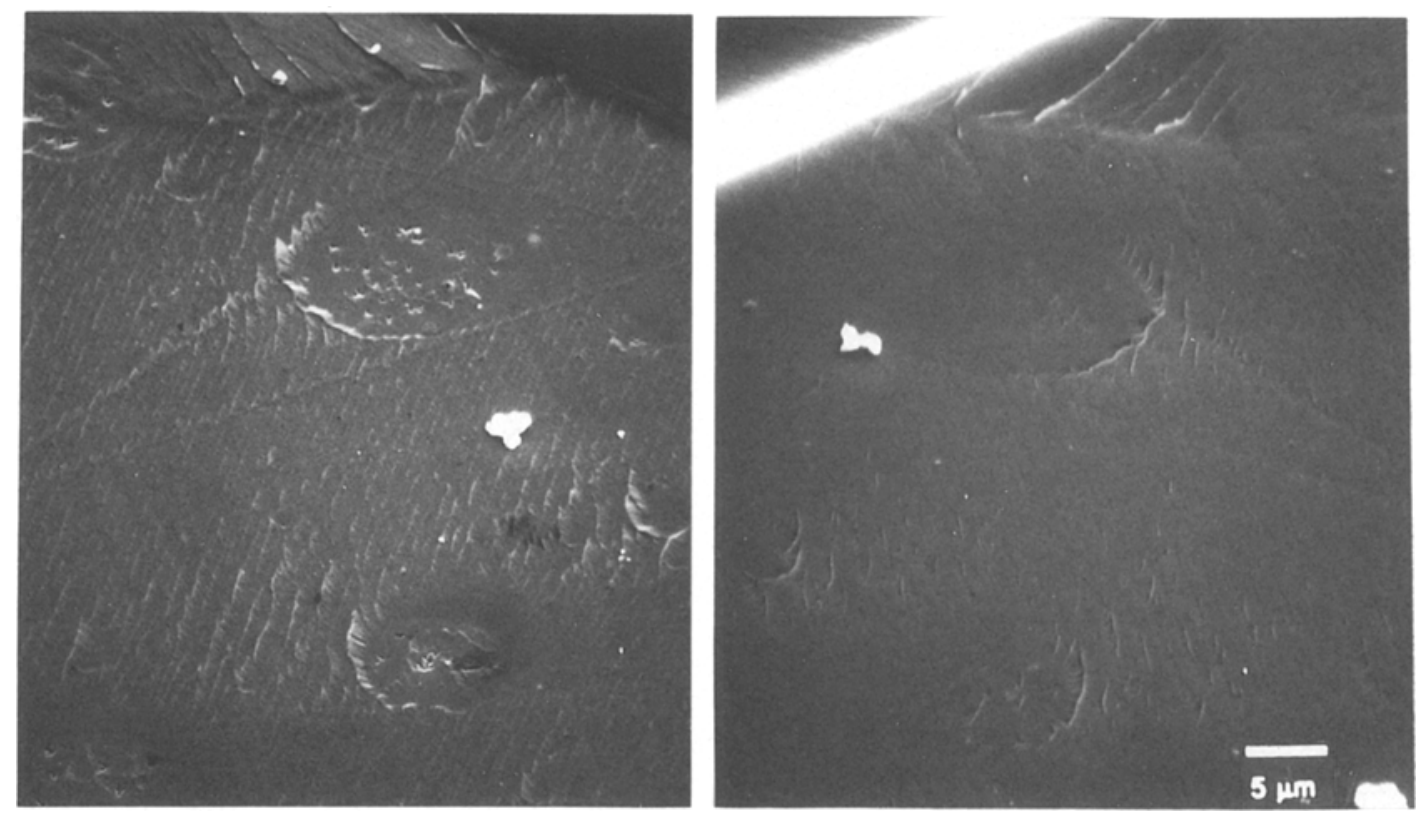

Figure 16 Higher magnification of Fig. 15, showing significant amounts of micro-ductility. The crack travelled (generally) upward.

observed with the slower crack-propagation speed specimens is rarely seen with the high speed specimens.

\subsection{Optical fractography of the interface}

Optical micrographs were obtained to supplement the SEM micrographs, and because of the transparency of the epoxy, observations could be made below the fracture surface. Optical microphotography was especially practicable because of the planar fracture surfaces created during fracture along the bond line. Without flat surfaces, such photographs are more difficult to obtain. Three methods of observation were used: normal bright field, polarized bright field, and dark field illumination.

The interface exposed by fracture of the age 0 specimens showed under normal bright field illumination a faint, barely discernable texture on the new surface.
The old mating surface showed less. Viewing the same surfaces under polarized light enhanced the texture considerably, and an example is shown in Fig. 21. The texture is a wavy, periodic texture with ridges running perpendicular to the crack direction. This is not the basic longitudinal texture. The ridges are highly continuous and look somewhat like topographical lines on a surveyor's map. The micrographs were taken with incident light through a polarizer oriented with respect to the analyser for maximum contrast. Again, the new surface, on the left, has the greater amount of deformation or texture, and the texture on the old surface is nearly invisible without polarized light.

A point worth noting is the difference in texture just prior to arrest, compared to that just after initiation. Just after initiation the texture is well-defined and
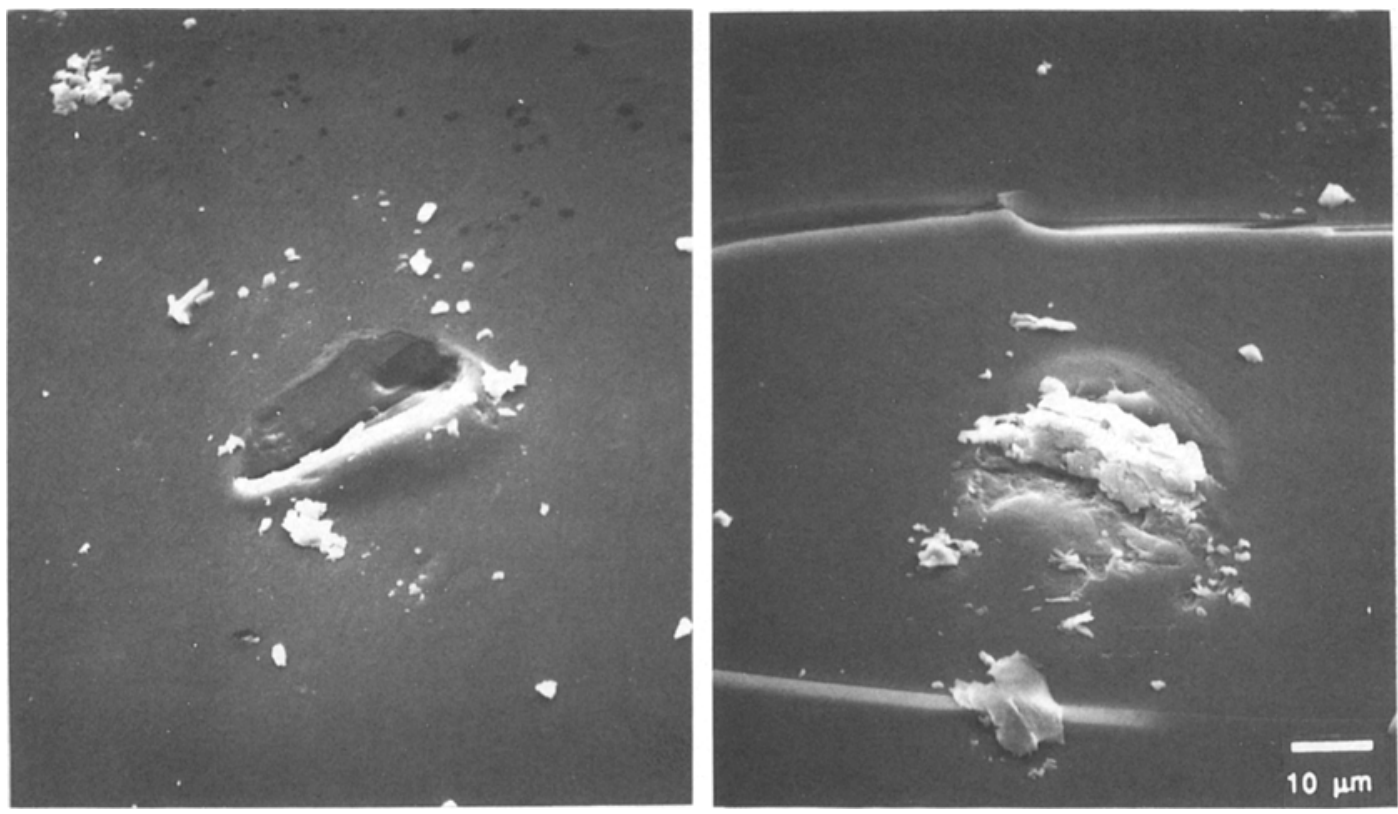

Figure 17 Commonly seen small feature with large amounts of deformation and microductility (age III specimen). 


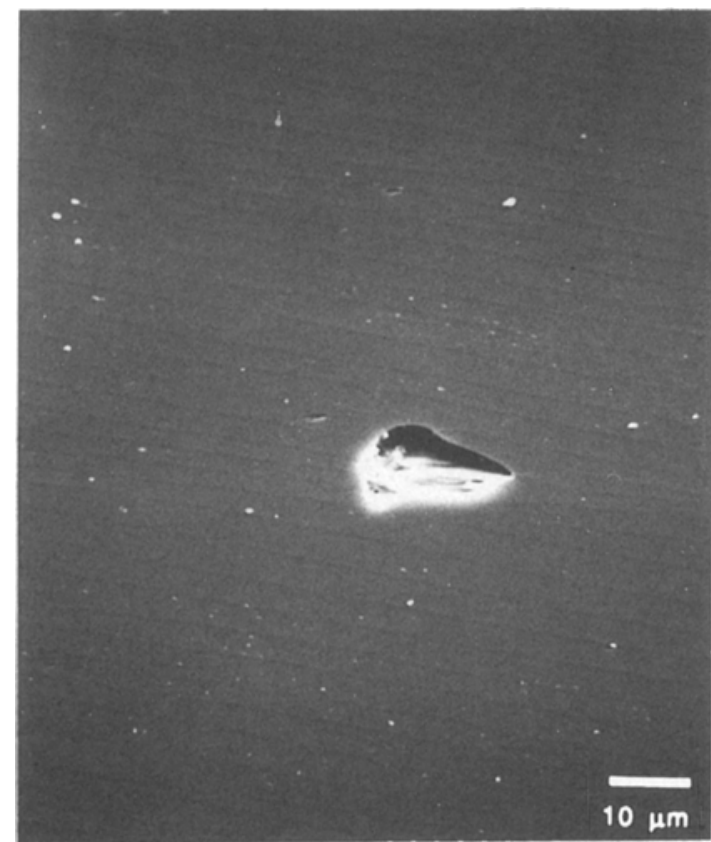

Figure 18 Interface of the new surface of an age 0 specimen broken by chisel and hammer. Parallel ridges of plastic deformation aligned in the fracture (horizontal) direction. The rows have a spacing in this micrograph of $\sim 4 \mu \mathrm{m}$. The triangle feature is a small feature of local toughness and was used to establish the mating surface.

periodic; just prior to arrest the height of the features appears less, and the periodicity less regular. These differences can be seen in Fig. 22.

On age I specimens is seen a texture on the corresponding surfaces that is not wavy, but rather pebbly. The texture occurs between the arrest lines and was enhanced by polarized light; it is shown in Fig. 23. A problem with observations using polarized light is that rotating the plane of polarization changed the topography of the surface. As a result, no conclusion could be drawn on what is protruding and what is

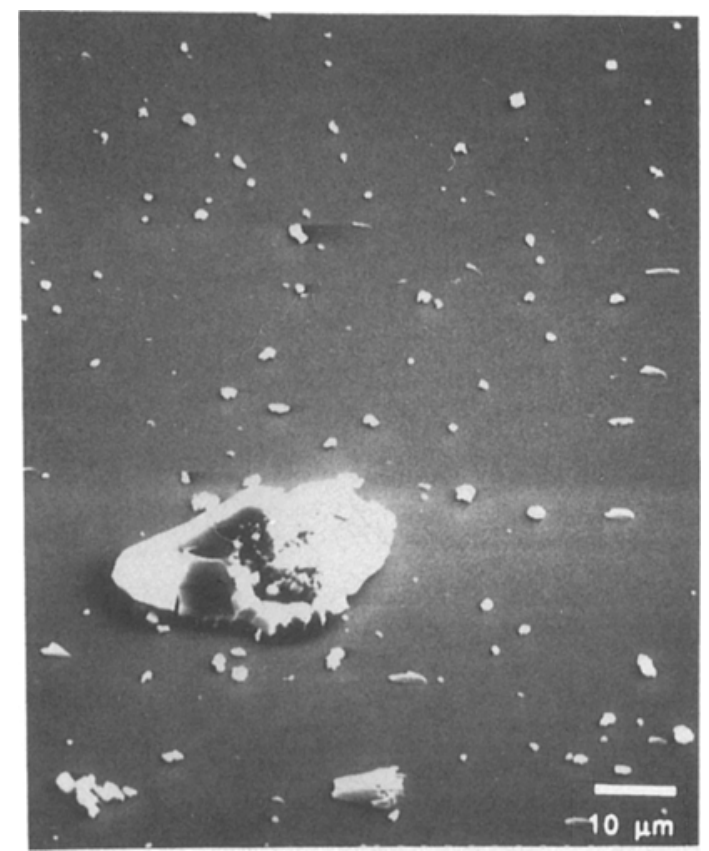

Figure 19 The old surface nearly mating the surface of Fig. 18. A faint texture corresponding to the deformation on the mating surface may be visible, but the scan lines of the SEM make confirmation difficult.

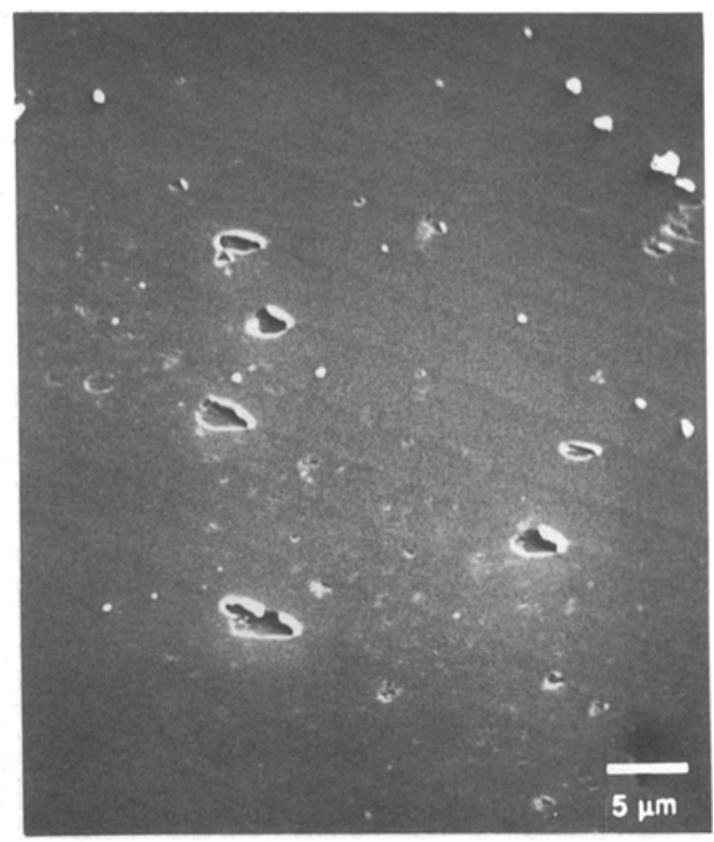

Figure 20 New surface of an age 0 specimen after high-speed fracture. Local areas of adhesion dispersed on large featureless planes; similar to surface seen from low-speed fracture (e.g. Fig, 17).

depressed. Both surfaces appeared pebbly, but the correspondence between the mating surfaces could not be established.

There was a very faint texture even under unpolarized white light for age II specimens, which always appeared on the new surface. The texture on the older, mating surface was less. The texture again was wavy, although smaller in size than that seen on the age 0 surface in Fig. 21.

Age III specimens show no significant features under any type of illumination. These specimen surfaces appeared completely featureless except for the occasional large features as described previously.

Polarized light gives the ability to view the effects of shear deformation in the material. Those features observed using polarized light are due to subsurface shearing occurring during crack propagation. The features observed using unpolarized white light may have been on the surface, although due to the transparent nature of the material, they may in fact have been slightly below the surface. The final word was given by dark field optical microscopy, however. Dark field micrographs indicated very flat surfaces, more so than was indicated by the unpolarized bright field micrographs.

\subsection{Fractography: leaving the interface}

On leaving the interface, the crack is found to behave in one of two ways: it may depart rather abruptly and at large angle, or it may leave gradually. The latter can be seen in Fig. 24. Approximately $50 \mu \mathrm{m}$ before beginning to leave the interface, the crack had stopped at an arrest line, which is tilted to the left of vertical in Fig. 24 and is located roughly $50 \mu \mathrm{m}$ to the left of the right side of the micrograph. Starting from the arrest line, the crack re-initiated, dropped away from the interface into the new bulk material, propagated for a short distance, then reversed course, crossing over the 

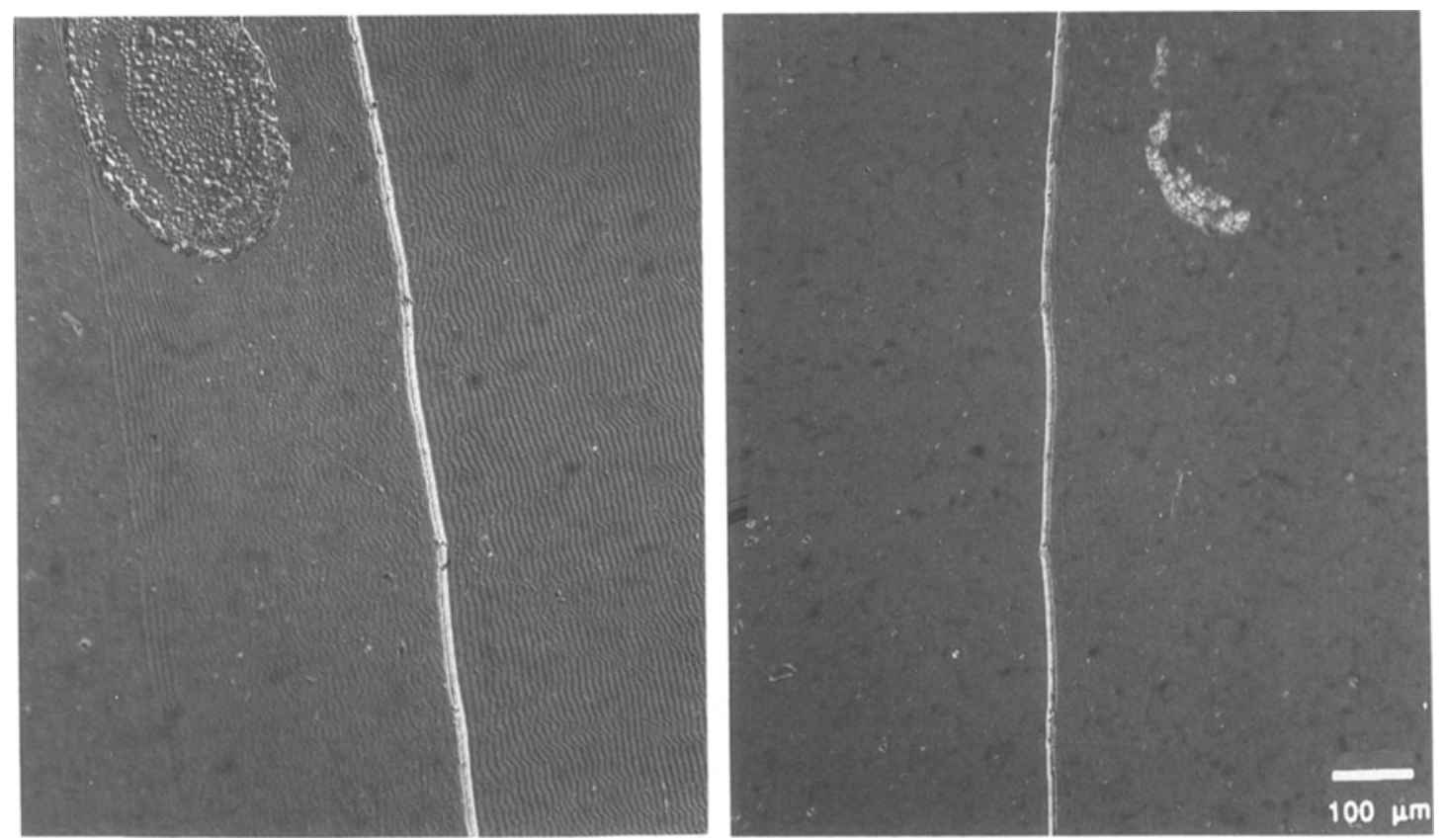

Figure $2 I$ Optical micrographs of the interface of an age 0 specimen using incident polarized light. The crack travelled toward the centre from the left and right edges, respectively. The vertical line is an arrest line. The "new" surface on the left contains nearly all the deformation caused by fracture.

interface, and finally left the interface forever into the old bulk material.

A more typical observation of the manner by which cracks leave the interface can be seen in Fig. 25. For no apparent reason, the crack simply leaves the interface at a rather large angle. For high-speed fracture, this is the only manner by which the cracks leave the interface: no evidence of gradual leaving was found.

When the crack travels along the interface and occasionally strays from the interface before returning to it, it usually strays into the new material. When the crack leaves for good, however, there is tendency for it to leave into the old side. Of eight times, with two specimens from each age group, the crack left the interface into the old bulk material seven times.

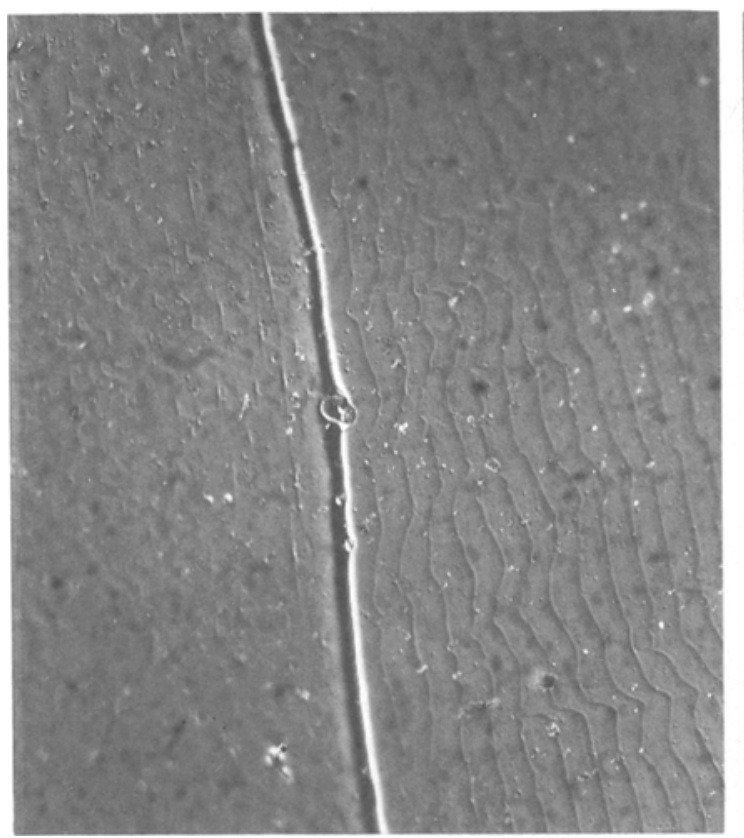

\section{Discussion}

\subsection{Fracture energy measurements}

The fracture energies measured were nearly as expected. The highest fracture energies were for bulk material, and the magnitudes were independent of ageing for up to $8 \mathrm{~h}$ at $200^{\circ} \mathrm{C}$ within statistical confidence. There was considerable statistical scatter in these measurements, however. The fracture energy for fracture along the bondline was less than that in the bulk, and the magnitude decreased as the surface to which bonding would be made was aged at $200^{\circ} \mathrm{C}$.

The method used in the present work for measuring the fracture energy, by driving a wedge into the material and measuring the crack opening and crack length, appears to give results comparable to those of

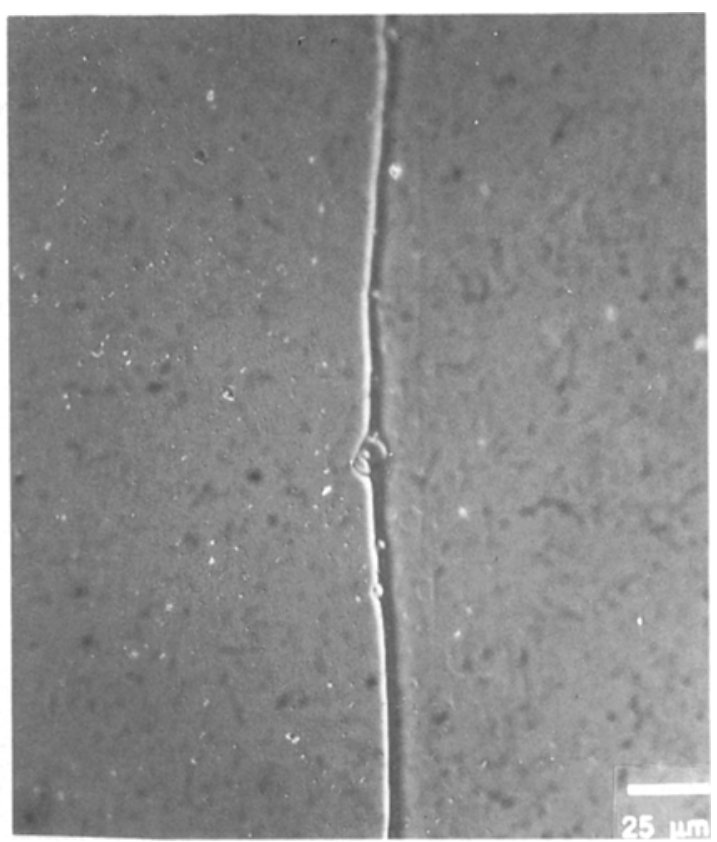

Figure 22 Enlargement of Fig. 21, showing the differences in texture after initiation and prior to arrest. The crack travelled from the edges to the center. The texture, due to subsurface shearing, is highly regular after initiation, but less so prior to arrest. 


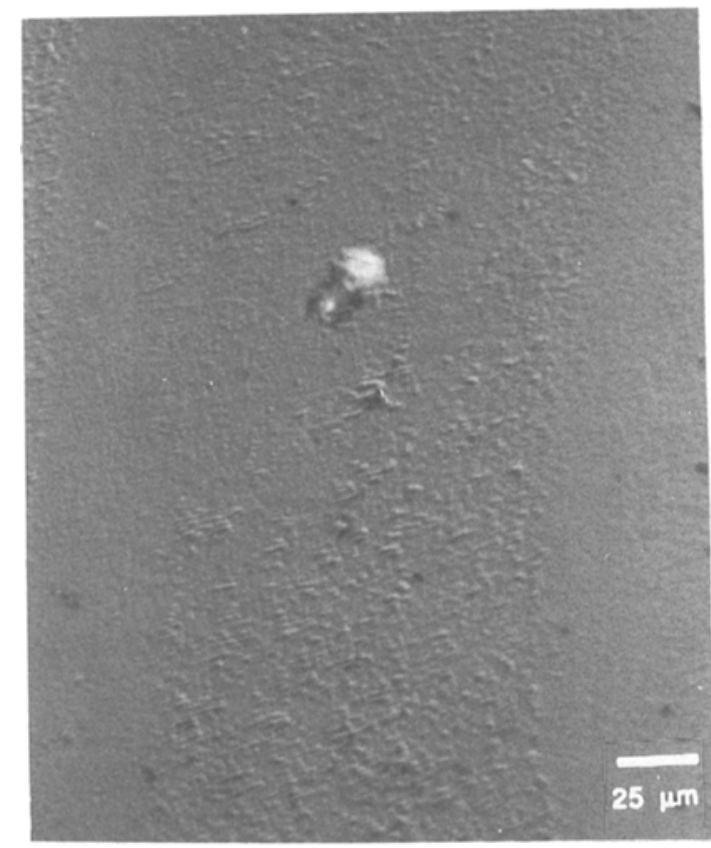

Figure 23 Optical micrograph of an age I fracture surface using incident polarized light. The surface exhibits an irregular, pebbly texture, unlike that seen on the age 0 specimen in Fig. 21, but still indicative of ductile flow.

other methods. Double torsion tests on the same bulk material, for example, resulted in fracture energy values ranging from 0.15 to $0.39 \mathrm{~kJ} \mathrm{~m}^{-2}$, with a mean value of $0.21 \mathrm{~kJ} \mathrm{~m}^{-2}$ [9]. This is the same mean value as that obtained in this work. Also, values of 0.1 to $0.3 \mathrm{~kJ} \mathrm{~m}^{-2}$ are commonly cited in the literature for the fracture energy of epoxies.

The large variance in fracture energy measurements for bulk fracture is common for very brittle materials [6]. A recent and detailed examination of this indicates

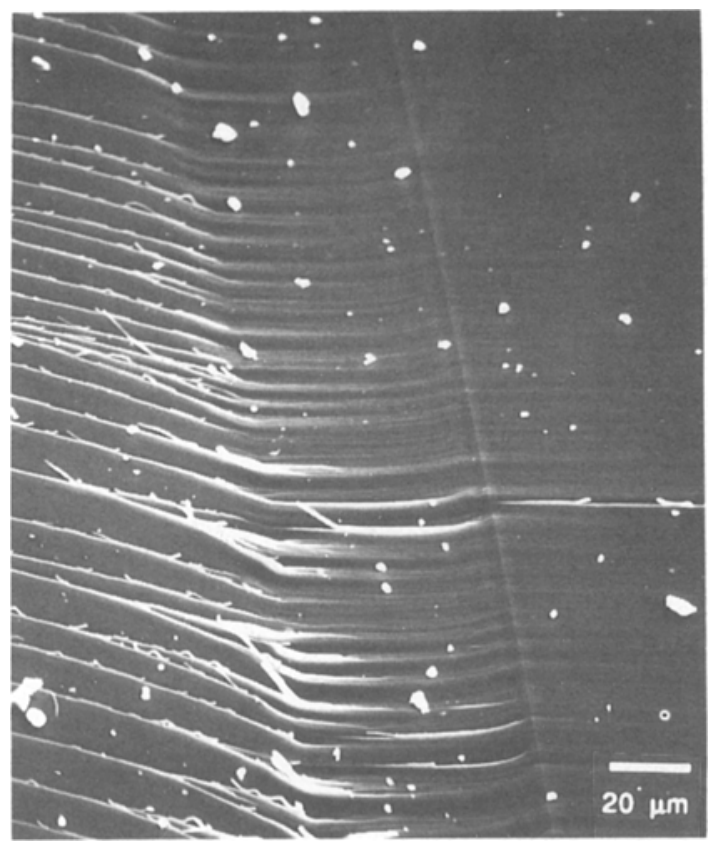

Figure 24 Gradual leaving of the crack from the interface. Beginning at an arrest line, which runs vertically roughly $50 \mu \mathrm{m}$ from the right edge of the micrograph, and travelling from right to left, the crack left the interface and dropped into the new bulk material, travelled for $\sim 50 \mu \mathrm{m}$, reversed direction and crossed the interface, and left into the old bulk material (age I).

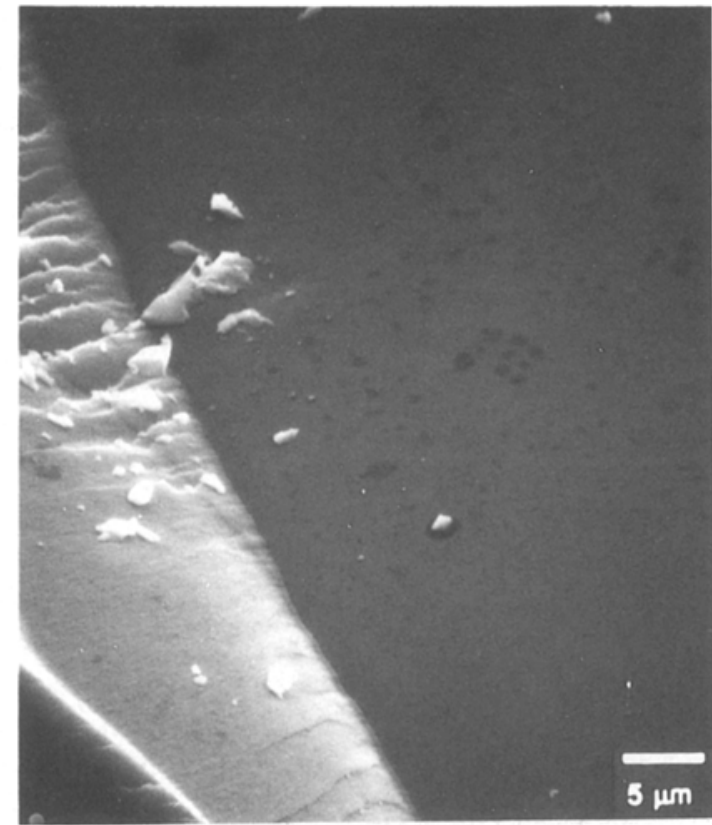

Figure 25 Typical sudden and steep leaving of the crack from the interface. The crack travelled from the interface in the upper right to the bulk in the lower left.

that the measured fracture energy correlates with the degree of fracture surfaces roughness, which in turn seems to depend on the vicissitudes of local material properties and stress fields [10].

Although the variance in the fracture energy measurements for the bulk is large, that for fracture along the interface is less so and shows the effects of ageing. The mean fracture energy for the unaged (age 0 ) bondline was roughly two-thirds that of the bulk fracture, 0.13 against $0.21 \mathrm{~kJ} \mathrm{~m}^{-2}$. The variance and magnitude of the fracture energies of the bonded specimens, decreased further with ageing.

The best fit to the fracture energy against ageing time data is given by the power-law expression in Equation 4. A dependence on time raised approximately to the one-third power is reminiscent of creep [11], although the driving force in the latter case is mechanical stress while that in the present case is more likely to be surface energy. But the response of the necessary segmental rearrangements may be similar. Although treating cure and postcure as being equivalent to $0.55 \mathrm{~h}$ at $200^{\circ} \mathrm{C}$ is not justified by a typical Arrhenius rate dependence on temperature for a reasonable and constant activation energy (it is too long a time at $200^{\circ} \mathrm{C}$ ), it does seem justifiable by the fact that concomitant with the higher fluidity of the epoxy during which cure and postcure occur, the activation energy would be lower. That is, the fluidity of the system during which cure and postcure occur allows such ageing processes as surface inversion and crosslinking, for example, to occur at least as rapidly as they will later at $200^{\circ} \mathrm{C}$.

Although the fracture energies of the bonded specimens were notably smaller than those of the bulk, the fracture energy remained significant. The mean fracture energy of the age 0 specimens $\left(0.13 \mathrm{~kJ} \mathrm{~m}^{-2}\right)$, for example, was still within the range of experimental values for the bulk. And after the $8 \mathrm{~h}$ of ageing at 
$200^{\circ} \mathrm{C}$ before bonding, the fracture energy $(0.050 \mathrm{~kJ}$ $\mathrm{m}^{-2}$ ) was still greater than one-fifth of the mean fracture energy for the bulk $\left(0.21 \mathrm{~kJ} \mathrm{~m}^{-2}\right)$. These changes in fracture energy might be compared with the rather precipitous decreases in fracture energy of the thermoplastics polystyrene [12] and poly(methyl methacrylate) [13] as the molecular weight decreases below about $10^{5}$. For example, the fracture energy for narrow-molecular-weight-distribution polystyrene plummets from a value in the range of $100 \mathrm{~J} \mathrm{~m}^{-2}$ to about $2 \mathrm{~J} \mathrm{~m}^{-2}$ as the molecular weight decreases from 111000 to 35000 .

\subsection{Possible causes of interfacial weakness}

The causes of weakness at the bond line of adhesive bonds are rarely easy to discover, nor do they usually arise from a single source. In the present case of a thermally aged epoxy, the following list can be considered: lack of covalent bonding across the interface; poor wetting by the bonding epoxy caused by a low energy surface to be bonded to, possibly arising from selective orientation of surface molecular segments or to external contamination; weak interfacial layer of uncured or non-fully cured epoxy, possibly due to oxidation or to loss of curing agent or accelerator by evaporation; or a discontinuity in elastic properties at the interface owing to the development of different moduli on the two sides.

Although none of the above possible causes of interfacial weakness can be eliminated, the following observations reduce the likelihood of the last two. In a series of experiments in which an excess of curing agent was added to the bonding (newer) epoxy, some of this curing agent was found to have diffused into the older epoxy during the process of curing and postcuring. This was observed as a staining of the older epoxy, to a depth of the order of $0.1 \mathrm{~mm}$, by the highly-coloured curing agent. The staining was observed for each of the aged specimens, and their fracture behaviour was the same as for those for which a stoichiometric amount of curing agent was used for both layers. Thus, the lowering of the fracture energy by ageing is not likely to be due to an incomplete cure owing to a lack of curing agent. Moreover, the epoxy system has considerable ability to dissolve and swell uncured material, and should assist the curing reaction further and even be able to disperse a residual uncured layer away from the surface. Thus, a significantly uncured epoxy layer is unlikely to exist at the bondline after the second cure and post-cure treatments, making the presence of an uncured layer an unlikely mechanism for the reduction in bond strength by ageing.

The hypothesis of a discontinuity in elastic properties at the bond line is also unlikely. The elastic moduli of glassy epoxies are generally observed not to be greatly affected by ageing, and indeed the two sides of age 0-type specimens were found to have the same modulus within experimental error.

Therefore, the first two suggested causes of bond strength loss with ageing seem the more likely: the loss of covalent bonding across the interface and the incomplete wetting or spreading on the surface to be bonded of the bonding epoxy system. Of these, the loss of covalent bonding across the interface is expected to be especially affected. Complete cross-linking is not achieved after usually postcuring [14], which allows some chemical bonding across the interface with the age 0 specimens. But ageing should continue the crosslinking reaction, thus decreasing the amount of chemical bonding possible across the interface. Since ageing is thought to cause chain scission as well as crosslinking [15], however, a balance between cross-linking and scission may occur, though scission may not produce functionality for equivalent cross-linking.

\subsection{Effects of interfacial weakness on fracture}

Channelling in its various forms of the propagating crack is the principal effect on fracture of interfacial weakness. Channelling is greater in specimens aged longer and having lower fracture energy. The fracture surfaces reflect this. For instance, lower fracture energy surfaces have fewer ductile features. Interfacial ductility seems ultimately to lead to the interruption of crack channelling and deflects the crack away from the interface into the bulk material.

The fractographic study of surfaces created during slow crack growth, obtained during the fracture energy measurement, has revealed the character of the bond line's apparent proclivity to channel the crack and its seeming antagonist, ductile behaviour. The bond line often seemed to attract cracks in the bulk straight toward it when the cracks were within tens of micrometres of it. Sometimes, however, perhaps after a strong attraction of the crack to the vicinity of the bond line, a feathered approach to the bond line itself, extending over a distance of up to $\sim 100 \mu \mathrm{m}$, was allowed. While travelling along the bond line, the fracture was often allowed to deviate a few micrometres into the bulk, usually into the newer side, and travel partially through it parallel with the bond interface. This behaviour was not observed with highspeed fracture, however. With high-speed fracture, ridges several micrometres apart and parallel with the direction of crack propagation were observed on the newer surface. With low-speed fracture, rather than ridges on the surface parallel with the fracture direction, there were sub-surface undulations, stronger in the newer bulk and best seen with polarized incident illumination, that were perpendicular to the direction of crack propagation. The intensity of the undulation decreased with ageing. With both high- and low-speed fracture and with the crack travelling along the interface, many instances were found where pieces of the bulk were plucked essentially from one of the sides and left attached to the other. The pieces, some micrometres in diameter, had about the same thickness or height as diameter. In spite of the channelling effect of the bond line, the fracture often escaped. Like cracks approaching the bondline, the leaving occurred both abruptly, with the crack leaving along a demarcated curve and at high angle, and gradually, with the crack leaving at a low but increasing angle.

Some of these features of the fracture surface may have simple explanations. The tendency for the crack 
to deviate a few micrometres from the bond line into the bulk and travel partially through it parallel with the bond interface may arise simply as a crack propagation instability, for example. The greater excursions from the interface made by the crack path, in the range of 100 to $1000 \mu \mathrm{m}$, may have been caused by singular and adventitious events on the interface: a scratch from handling or an area in which the material had been plasticized due to an impurity, for example. Or perhaps changes in the stress field or local material properties are sufficient to deflect the travelling crack from the interface at a high angle.

The majority of fracture surface features suggest that the channelling effect of the bond line exists largely at higher strains, where the material behaves inelastically or plastically, and not at lower strains, where the material behaves elastically. The two sides of the bond seem not to differ much in elastic modulus. On the other hand, their yield stresses and ductile behaviour seem significantly different, with the aged material being more brittle and having the higher yield stress. A consistent difference between the two is derived from the appearance of ductile areas on the interface. The more ductile material is always the new resin. The older, more highly cross-linked material is never plastically deformed. The differences in ductility between old and new resin increased with increased ageing time. To the extent that the crack path is determined by the elastic stress field far in advance of the crack tip, the bond line could be invisible. The principal effect of the interface in guiding the crack would occur, then, only at higher strains, probably behind the primary crack tip, thus affecting mainly the secondary fracturing processes. In this way, both the abrupt and the feathered approach toward and away from the bondline can easily exist side by side, probably being induced by different branches of the crack. Another type of feathering fracture that suggests a nearly invisible bond line is seen in the bulk-like features observed in the open areas between arrest lines, as in Fig. 11. These areas display bulk features but clearly remain within the channelling influence of the interface.

The generally high adhesive strength of the bond line is indicated by the plastic deformation of at least the newer side of the bond, the ridges on the surface parallel with the fracture direction at higher speeds, and the subsurface undulations perpendicular to the fracture direction at lower speeds. Such plastic deformation can occur only in the presence of moderately strong adhesion. Only with such adhesion would the stress necessary to deform the subsurface material be generated. A comparison of the specimens reveals a decreasing amount of plastic deformation as the ageing time of the specimens increased, corresponding to a decrease in fracture energy and bond strength.

Somewhat surprisingly, the subsurface plastic deformation at low speeds is exhibited in specimens having little apparent surface deformation. The optical micrographs reveal the subsurface shear strain in the form of serpentine lines perpendicular to the crack direction, as seen in Fig. 21. This deformation is always greater on the new side of the bilayer. As the material loses strain energy with continued cracking, the regularity and intensity of the deformation seem to decrease until the crack arrests. When testing continues, the energy required for initiation is stored as elastic energy in the specimen arms, and immediately after initiation the stored energy is greater than that required for simple propagation. As a result, excess energy can be diverted to secondary, subsurface deformation, and the periodicity is quite regular and the intensity large. The periodicity of the deformation is probably akin to the pulsation seen at the crack front during the debonding from a glass surface [8]. The pulsation seems directly analogous to stick-slip phenomena, and involves alternating fast and slow crack growth. During slow crack growth, the material undergoes shear softening, perhaps assisted by a temperature increase at the crack tip. As the region of softening ahead of the stagnated or slowly moving crack grows, progressing along the interface and below it, the region deforms and the material separates at the interface. Following this, the crack seems to spurt ahead with little or no deformation of the material, to be succeeded by a progressive softening that results in another region of deformation downstream.

Fracture features not readily explained, however, are the many instances, with both high- and low-speed fracture, where pieces of the bulk were plucked from one of the sides and left attached to the other surface as the crack travelled along the interface. These instances may indicate regions of greater adhesion, though the reasons for their existence is not known.

\section{Conclusions}

This work has attempted to quantify and reveal the reason for why adhesive bonds to aged surfaces are weak. But much remains unanswered. First, we have examined but a single, though we believe typical, system that was aged in a particular way: by shorttime ageing at a high temperature. Second, the likely hypotheses for the weakness of the bondline, a lack of covalent bonding across the interface and, perhaps, incomplete wetting by the bonding material to the interface, which are exhibited during plastic deformation, are unproven. And third, better procedures for overcoming such bond weakness were not discovered in this work, though possible hints for such might have been revealed by the occasional chunks of material that were plucked from one side and left attached to the opposite surface. Both the importance and challenge of the problem of bonding to aged surfaces would seem to warrant much further study.

\section{Acknowledgements}

We would like to acknowledge useful discussions with Ms Ju Covavisaruch and with Dr Ray Dickie of the Ford Motor Company, and the gift of the resin and curing agent by the Shell Chemical Company.

\section{References}

1. V. B. GUPTA et al., J. Mater. Sci 20 (1985) 3439.

2. R. E. ROBERTSON and V. E. MINDROIU, Polym. Sci. Engng 27 (1987) 55. 
3. J. E. MASTERS et al,, in "Engineered Materials Handbook", Vol 1: "Composites" (ASM International, Metals Park, Ohio, 1987) p. 765.

4. W. J. CANTWELl, A. C. ROULIN-MALONEY and T. KAISER, J. Mater. Sci. 23 (1988) 1615.

5. M. F. KANNINEN, Int. J. Fracture 9 (1973) 83.

6. R. E. ROBERTSON, J. Adhesion 7 (1975) 121.

7. R. E. ROBERTSON, V. E. MINDROIU and M. F. CHEUNG. Compos. Sci. Tech. 22 (1985) 197.

8. R. E. ROBERTSON et al., J. Mater. Sci. 24 (1989) 4106.

9. J. S. COVAVISAR UCH, private communication (1988).

10. J. S. COVAVISARUCH, J.-K. KIM, and R. E. ROBERTSON, to be published.

11. R. P, KAMBOUR and R. E. ROBERTSON, in "Poly- mer Science" Vol. 1, edited by A. D. Jenkins (North-Holland, Amsterdam, 1972) p. 687.

12. R. E. ROBERTSON, in "Toughness and Brittleness of Plastics," edited by R. D. Deanin and A. M. Crugnola (Americal Chemical Society, Washington, 1976) p. 89.

13. R. P. KUSY and D. T. TURNER, Polymer 17 (1976) 161.

14. A. ANKARA, D. WEISGERBER and J. VILSMEIER, Mater. Sci. Tech. 2 (1986) 647.

15. S. T. J. PENG, J. Mater. Sci. 20 (1985) 1920

Received 8 March

and accepted 30 August 1989 